Article

\title{
Evolution of the Microstructure and Lamellar Orientation of a $\beta$-Solidifying $\gamma$-TiAl-Based Alloy during Hot Compression
}

\author{
Kai Zhu ${ }^{1}$, Shoujiang $Q u^{1}$, Aihan Feng ${ }^{1}$, Jingli Sun ${ }^{2}$ and Jun Shen ${ }^{1, *(D)}$ \\ 1 School of Materials Science and Engineering, Tongii University, Shanghai 201804, China; \\ 1zhukai@tongji.edu.cn (K.Z.); qushoujiang@tongji.edu.cn (S.Q.); aihanfeng@tongji.edu.cn (A.F.) \\ 2 Shanghai Spaceflight Precision Machinery Institute, Shanghai 201600, China; sunjingli1221@126.com \\ * Correspondence: junshen@tongii.edu.cn; Tel.: +86-21-6958-1009
}

Received: 11 May 2018; Accepted: 5 June 2018; Published: 11 June 2018

\begin{abstract}
A type of advanced $\gamma$-TiAl-based alloy called $\beta$-solidifying $\gamma$-TiAl has elicited remarkable research interest in the last few decadesbecause of its excellent workability and homogeneous microstructures. Thermomechanical treatments are widely applied to this alloy to obtain fine duplex microstructures. To investigate the deformation behavior and microstructure evolution of Ti-44Al-4Nb-1.5Cr-0.5Mo-0.2B alloy, we conducted a series of hot compression tests at a temperature of $1473 \mathrm{~K}$ and a strain rate of $0.01 \mathrm{~s}^{-1}$. Scanning electron microscopy, electron backscattered diffraction, and transmission electron microscopy were performed to analyze the crystal orientation and microstructures of the alloy. During compression at $1473 \mathrm{~K}, \beta / \mathrm{B} 2 \rightarrow \gamma$ transition and $\alpha_{2} / \gamma$ lamellae $\rightarrow \gamma+\beta /$ B2 transition occurred simultaneously, which increased the content of the $\gamma$ phase and decreased the content of the $\alpha_{2}$ phase. The lamellar colonies exhibited distinct anisotropy, which could affect their hot deformation behavior. The colonies that remained after compression had strong texture components.
\end{abstract}

Keywords: $\gamma$-TiAl-based alloy; microstructure; lamellar orientation; electron backscattered diffraction

\section{Introduction}

Intermetallic $\gamma$-TiAl-based alloys are promising candidates for high-temperature structural application in the aerospace and automotive industries [1,2]. A type of advanced $\gamma$-TiAl-based alloy called $\beta$-solidifying TiAl has been recently developed [3]. This alloy usually contains relatively low $\mathrm{Al}$ content and $\beta$-stabilizing elements, such as $\mathrm{Nb}, \mathrm{Mo}$, and $\mathrm{Cr}$, which make the alloy solidify via the $\beta$-single phase field and maintain a certain amount of $\beta / B 2$ phase (B2 stands for ordered $\beta$ phase at low temperatures). Therefore, $\beta$-solidifying TiAl alloys always present excellent workability, fine and homogeneous microstructures, weak textures, and minimal segregation [4]. These characteristics make such alloys attractive not only in cast applications but also in thermomechanical processes. The aim of thermomechanical treatment of $\gamma$-TiAl-based alloys is to develop a refined and homogeneous microstructure that exhibits improved mechanical properties and a broad process window for secondary processing [5]. Despite the application of different thermomechanical treatments, such as forging, hot extrusion, and hot pack rolling, the microstructures inevitably transform from lamellar or near-lamellar structures into duplex ones [6-9]. Generally, a deformed microstructure is highly inhomogeneous because of the mechanical anisotropy of lamellar colonies and different intrinsic deformation mechanisms between colonies and phases situated at the colony boundaries [10]. Polysynthetically twinned (PST) crystals which are regarded as a single colony have been the subject of intensive studies on estimating yield stress as a function of lamellar orientation [11-13]. This condition 
indicates that tensile elongation and yield stress strongly depend on the orientation of PST crystals. Furthermore, micropillar compression experiments are frequently performed with $\gamma$-TiAl-based alloys to understand the deformation mechanisms and size effects with as minimal interference as possible [14,15]. However, the deformation mechanism of multi-phase TiAl alloys with random orientations of colonies remains unclear. Moreover, the phase transformations of $\beta$-solidifying $\gamma$-TiAl alloys often occur during hot deformation, which is associated with the phase-field temperature [16]. Unlike conventional engineering $\gamma$-TiAl-based alloys which only consist of $\gamma$ and $\alpha_{2}$ two phases, a significant amount of $\beta / \mathrm{B} 2$ phase often exists in $\beta$-solidifying $\gamma$-TiAl alloys. The phase transformation sequence is quite different, depending on the content and type of the $\beta$-stabilizing element and the content of the $\mathrm{Al}$ element [17]. However, the phase diagram of the alloy studied in this work is still unknown, and an alloy with a closer composition, called TNM, can be used as a reference. Below the eutectoid temperature, $\beta$-phase fraction increases with increasing temperature. When the temperature is over the eutectoid temperature, $\gamma$-phase and $\beta$-phasefraction decreases with increasing temperature. When the temperature reaches the $\gamma$-solvus temperature, $\alpha$-phase fraction reaches the maximum value and $\gamma$-phase seems to vanish [18]. Understanding the phase transformations and deformation mechanisms of $\beta$-solidifying $\gamma$-TiAl alloys is essential for optimizing the thermomechanical processes of these alloys.

This investigation aimed tounderstand the hot deformation behavior of Ti- $44 \mathrm{Al}-4 \mathrm{Nb}-1.5 \mathrm{Cr}-0.5 \mathrm{Mo}-0.2 \mathrm{~B}$ alloy during uniaxial hot deformation. Hot compression tests were conducted at a strain rate of $0.01 \mathrm{~s}^{-1}$ and a temperature of $1473 \mathrm{~K}$. The $\alpha_{2}$ colony orientation represented the entire colony orientation at the deformation temperature $(1473 \mathrm{~K})$, which was set to above the eutectoid temperature and situated inthe three-phase region. The $\alpha_{2}$ colony orientation and phase distribution were studied by electron backscattered diffraction (EBSD) method, and other details about phase transitions and deformation mechanism were studied using transmission electron microscopy (TEM) method.

\section{Materials and Methods}

In this work, a $\beta$-solidifying $\gamma$-TiAl-based alloy with a nominal composition of Ti-44Al-4Nb-1.5Cr$0.5 \mathrm{Mo}-0.2 \mathrm{~B}$ (in at. \%) was investigated. The cast ingot of this alloy was melted twice by a vacuum arc, remelting to obtain a billet with approximately $200 \mathrm{~mm}$ diameter and $500 \mathrm{~mm}$ length. Cylindrical samples with $8 \mathrm{~mm}$ diameter and $12 \mathrm{~mm}$ height were cut from the ingot by electrodischarge machining. The temperatures of the phase transitions in as-cast Ti- $44 \mathrm{Al}-4 \mathrm{Nb}-1.5 \mathrm{Cr}-0.5 \mathrm{Mo}-0.2 \mathrm{~B}$ alloy were investigatedby differential scanning calorimetry (DSC) experiments. The DSC test was performed at a heating rate of $20 \mathrm{~K} / \mathrm{min}$ under pure $\operatorname{Ar}(99.9999 \%)$ using a NetzschSTA449F3 heat flux calorimeter (NETZSCH Scientific Instruments Trading (Shanghai) Ltd., Shanghai, China). Hot compression tests were performed on a Gleeble 3500 machine (Dynamic Systems Industry, New York, NY, USA). As illustrated in Figure 1a, three samples were uniaxially compressed by $20 \%, 40 \%$, and $60 \%$ reduction in height and cut along the compression axis by electrodischarge machining. The metallography and microstructure observation positions are shown in Figure 1b. The metallograph shows that the deformed microstructures were uniform and sound. Figure 1c shows the hot compression process. The samples were heated up to $1473 \mathrm{~K}$ at a heating rate of $7 \mathrm{~K} / \mathrm{s}$ and the temperature was maintained at $1473 \mathrm{~K}$ for $120 \mathrm{~s}$ to ensure thermal homogeneity. The strain rate was $0.01 \mathrm{~s}^{-1}$. After compression, the samples were immediately quenched with water to maintain the thermo-mechanical treated microstructure features. The microstructures of the as-cast and as-compressed samples were investigated via scanning electron microscopy (SEM; Quanta 400 FEG, FEI Company, Hillsboro, OR, USA) in the backscattered electron (BSE) mode at an acceleration voltage of $20 \mathrm{kV}$. The phase distribution and crystal orientation were characterized by EBSD (Oxford Instruments, Oxford, UK) with step sizes of $0.1-0.15 \mu \mathrm{m}$ with a scanning electron microscope (Quanta 450, FEI Company, Hillsboro, OR, USA). The EBSD data were analyzed using the HKL Channel 5 software (Oxford Instruments, Oxford, UK). The samples were electrochemically polished with a $6 \mathrm{vol} \%$ perchloric acid, $34 \mathrm{vol} \%$ n-butyl alcohol, and $60 \mathrm{vol} \%$ methanol electrolyte operating at $60 \mathrm{~V}$ and $-30{ }^{\circ} \mathrm{C}$ for SEM and EBSD 
characterization. The phase composition of as-cast and hot compression samples was determined using X-ray diffraction (XRD) on XD-6 machine (Persee Inc., Beijing, China). TEM characterization was conducted on a JEM-2100F (JEOL Ltd., Tokyo, Japan) at an acceleration voltage of $200 \mathrm{kV}$. Thin foils prepared for TEM analysis were mechanically polished to a thickness of 60-80 $\mu \mathrm{m}$ and twin-jet polished with a $6 \mathrm{vol} \%$ perchloric acid, $34 \mathrm{vol} \%$ n-butyl alcohol, and $60 \mathrm{vol} \%$ methanol electrolyte operating at $45 \mathrm{~V}$ and $-30^{\circ} \mathrm{C}$.

(a)

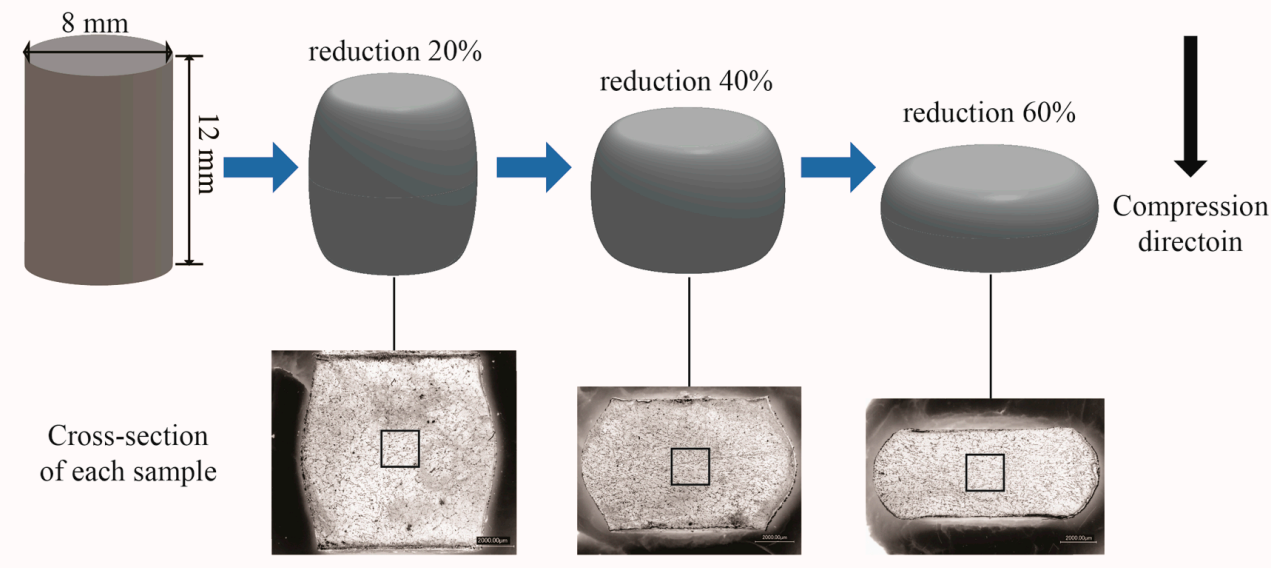

(c)

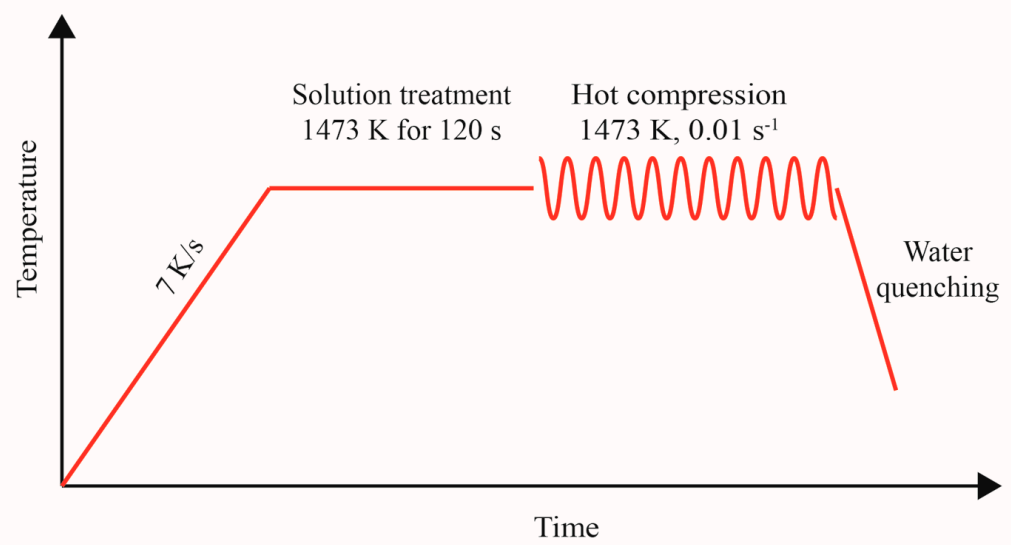

Figure 1. (a)Processing parameters of thermomechanical treatment; (b) diagram of samples after thermomechanical treatment. The black arrow shows the compressive direction; (c) metallograph of each sample. The black rectangle marks the microstructure observation position.

\section{Resultsand Discussion}

\subsection{Initial Microstructure}

The initial microstructure of the as-cast Ti-44Al-4Nb-1.5Cr-0.5Mo-0.2B alloy for the hot compression experiments is presented in Figure 2. Figure 2a shows that the as-cast microstructure mainly consisted of fine and homogeneous lamellar $\alpha_{2} / \gamma$ colonies surrounded by $\gamma+\beta /$ B2 two-phase mixtures. The average colony size was $\sim 100 \mu \mathrm{m}$. The features of the $\alpha_{2} / \gamma$ lamellae are further resolved in Figure $2 \mathrm{~b}$. The mean thickness of the $\gamma$ laths was $\sim 0.5 \mu \mathrm{m}$ and that of the $\alpha_{2}$ laths was $\sim 0.1 \mu \mathrm{m}$. The $\gamma$ and $\alpha_{2}$ laths satisfied the Blackburn orientation relationship determined by selected area electron diffraction (SAED) patterns [19]. Furthermore, the orientation of the $\alpha_{2}$ laths was the same,and six types of variants were found in the $\gamma$ laths in an entire colony [10]. The inverse pole figure (IPF) map (Figure 2c) shows the random grain orientation of the as-cast microstructure (most of the $\alpha_{2}$ laths in colonies were too thin to resolve), which confirms that the initial microstructure had a weak texture because of $\beta$ solidification. 

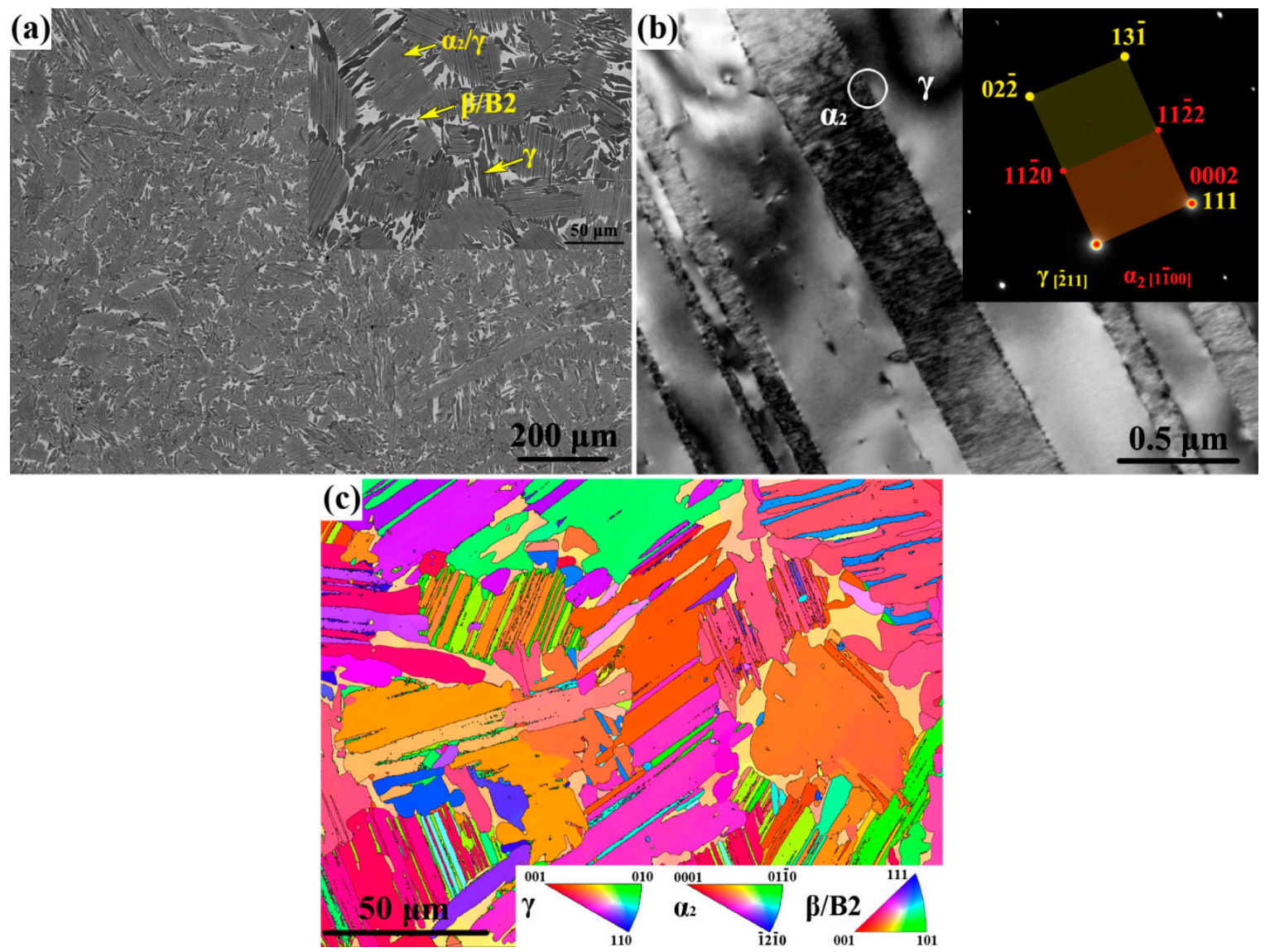

Figure 2. Microstructure of as-cast Ti-44Al-4Nb-1.5Cr-0.5Mo-0.2B alloy: (a) SEM image in BSE mode. The $\gamma$ phase is dark gray, the $\alpha_{2} / \gamma$ colonies are light gray, and $\beta / B 2$ is white; (b) TEM image of the $\alpha_{2} / \gamma$ lamella. The top-right corner image shows the corresponding SAED patterns of $\alpha_{2} / \gamma$ lamella, and the white circle marks the selected area; (c) IPF map.

\subsection{Uniaxial Hot Compression Tests}

Figure 3 shows the experimentally derived true strain-stress (S-S) curves from the hot deformation tests compressed to $20-60 \%$ reduction at a strain rate of $0.01 \mathrm{~s}^{-1}$ and a temperature of $1473 \mathrm{~K}$. The corresponding microstructures after hot compression are shown in Figure 4. All of the S-S curves show a pronounced stress peak in the early stage of compression. With increasing strain, the flow stress continuously decreased to a steady-state plateau. Commonly, the stress peak is related to the competition effect between work hardening and flow softening (i.e., dynamic recrystallization (DRX), flow instability etc.) [20]. After the stress peak, the DRX softening mechanism dominatedthe competition, and the defect density decreased. The DRX process began at a low strain $(\varepsilon=0.05$ to 0.1) [16]. After $20 \%$ compression, the microstructure (Figure 4a) of Sa (Sa presents the $20 \%$ compressed sample) changed slightly compared with the initial microstructure (Figure 1a). Several lamellar colonies were bended or kinked. Tiny lens-shaped $\gamma$-grains $\left(\gamma_{\text {lens }}\right)$ were observed within the $\beta / B 2$ phase and further analyzed by TEM. As the compression increased to $40 \%$, numerous kink bends and bent lamellae were observed, as indicated in Figure 4b, which shows the microstructure of $\mathrm{Sb}$ (Sb represents the $40 \%$ compressed sample). The colony size of Sb decreased compared with that of Sa (Figure 4a) due to the spheroidization and fragmentation of the lamellae and the DRX in the $\gamma+\beta /$ B2 mixtures. Parts of the lamellar colonies rotated or elongated because of local stress. When the compression reached $60 \%$, the deformed microstructure (Figure 4c) of Sc (Sc represents the $60 \%$ compressed sample) primarily consisted of remnant lamellar colonies and $\alpha_{2}+\gamma+\beta /$ B2 mixtures situated among colonies. Additionally, the remnant lamellar colonies were fine and had a preferred 
orientation. The deformation behavior of $\beta$-solidifying $\gamma$-TiAl-based alloys exhibits different features, which depend on the specific phase field region in which hot deformation is produced [16,21]. Given that the compression temperature was $1473 \mathrm{~K}$ in this work, within the $\left(\alpha / \alpha_{2}+\gamma+\beta / \mathrm{B} 2\right)$ field of the Ti-44Al-4Nb-1.5Cr-0.5Mo-0.2B alloy, the DRX process of $\gamma$ and $\beta / B 2$ grains, the spheroidization and fragmentation of the lamellae, the rotation of the lamellar colonies, and the phase transitions occurred simultaneously during compression. Therefore, the dynamic softening of the S-S curves was caused not only by the DRX process but also by the flow localization and phase transitions.

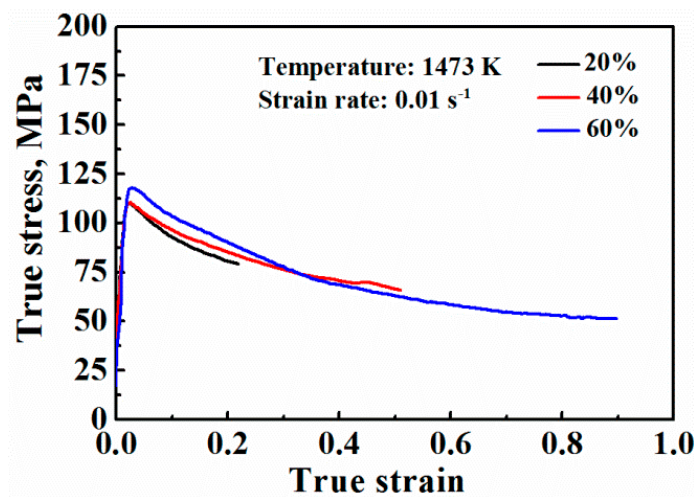

Figure 3. True stress-strain curves of the as-cast Ti-44Al-4Nb-1.5Cr-0.5Mo-0.2B alloy.
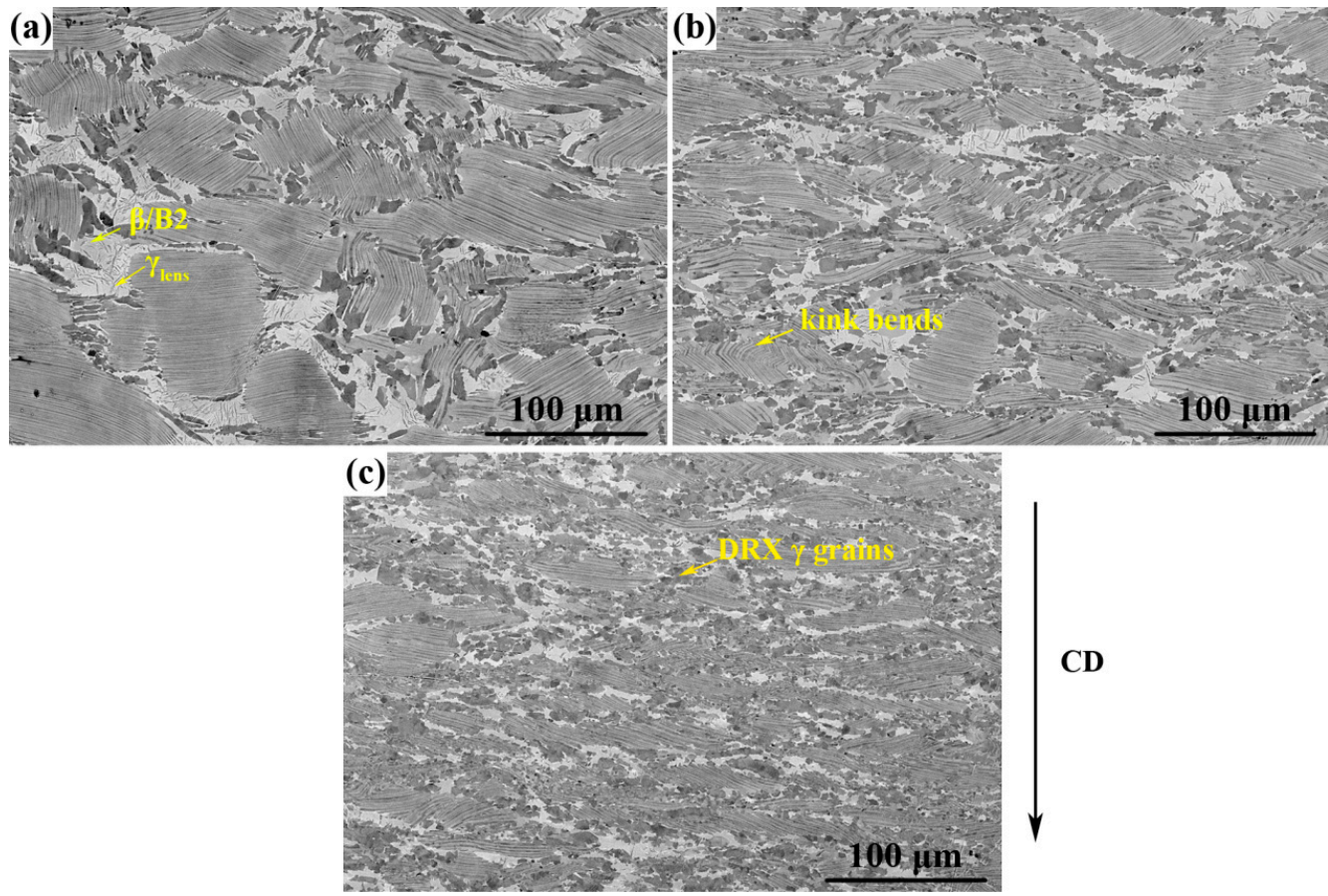

Figure 4. SEM images of Ti-44Al-4Nb-1.5Cr-0.5Mo-0.2B alloy compressed at $1473 \mathrm{~K}$ and a strain rate of $0.01 \mathrm{~s}^{-1}$ : (a) 20\% reduction; (b) 40\% reduction; and (c) 60\% reduction. CD denotes the compressive direction, and in all images, the compressive direction is vertical.

\subsection{Microstructure Evolution}

Figure 5a shows the central part of the Ti-Al phase diagram [22]. The eutectoid temperature $\left(\mathrm{T}_{\mathrm{eu}}\right)$ is very important in this phase diagram, over which the $\gamma+\alpha_{2} \rightarrow \alpha$ transition occurs. In the Ti-Al phase diagram, $\mathrm{T}_{\mathrm{eu}}$ is $1120^{\circ} \mathrm{C}(1393 \mathrm{~K})$. Figure $5 \mathrm{~b}$ shows the DSC trace of as-cast alloy. It indicates that $\mathrm{T}_{\mathrm{eu}}$ is $1178^{\circ} \mathrm{C}(1451 \mathrm{~K})$ and $\gamma$-solvus temperature $\left(\mathrm{T}_{\alpha}\right)$ is $1320^{\circ} \mathrm{C}(1593 \mathrm{~K})$. The eutectoid temperature rises due 
to $\mathrm{Nb}$ addition. Furthermore, since the phase transformations in Ti-Al system are sluggish, the phase transformation temperature might be higher than the actual value. Figure 6 shows the XRD patterns of as-cast alloy, $\mathrm{Sa}, \mathrm{Sb}$ and Sc. The XRD patterns of as-cast alloy illustrate that there are $\gamma, \alpha_{2}$, and $\beta / \mathrm{B} 2$ three phases in the initialmicrostructure, which is consistent with previous discussion (Section 3.1). However, the differences among the XRD patterns of Sa, Sb and $\mathrm{Sc}$ are not significant due to the fact that phase transitions during hot deformation are too subtle to be detected by XRD. Figure 7a-c shows the morphology and distributions of the different phases in $\mathrm{Sa}, \mathrm{Sb}$, and Sc, respectively. Figure 7d shows specific phase fractions in different states. In the as-cast microstructure, $\gamma, \alpha_{2}$, and $\beta / B 2$ accounted for $84.5 \%, 5.37 \%$, and $10.2 \%$, respectively. With anincrease in deformation, the content of the $\gamma$ phase increased from $34.5 \%$ to $53.3 \%$, whereas the content of the $\alpha_{2}$ phase decreased from $50.4 \%$ to $27.8 \%$. In the $\beta / \mathrm{B} 2$ phase, the regularity was not obvious. When the samples were heated to $1473 \mathrm{~K}$, which is above the eutectoid temperature [23], the $\gamma$ laths within the colonies began to dissipate, and the $\alpha_{2}$ phase became the matrix phase of lamellar colonies. This phenomenon can also be verified by the phase fraction in Figure 7a to a certain extent because deformation exerts no significant effect on the phase transitions. Meanwhile, the lens-shaped $\gamma$ grains precipitated from $\beta / \mathrm{B} 2$ grains even with small deformation, as shown in Figure 4a and Figure 9a. The deformation-induced $\beta / \mathrm{B} 2 \rightarrow \gamma$ transition probably occurred at $1473 \mathrm{~K}$. The variation law of the $\gamma$ and $\alpha_{2}$ phases during compression was mostly ascribed to $\alpha_{2} / \gamma$ lamellae $\rightarrow \gamma+\beta /$ B2 transition. Similar results have been reported by other studies $[21,24]$.
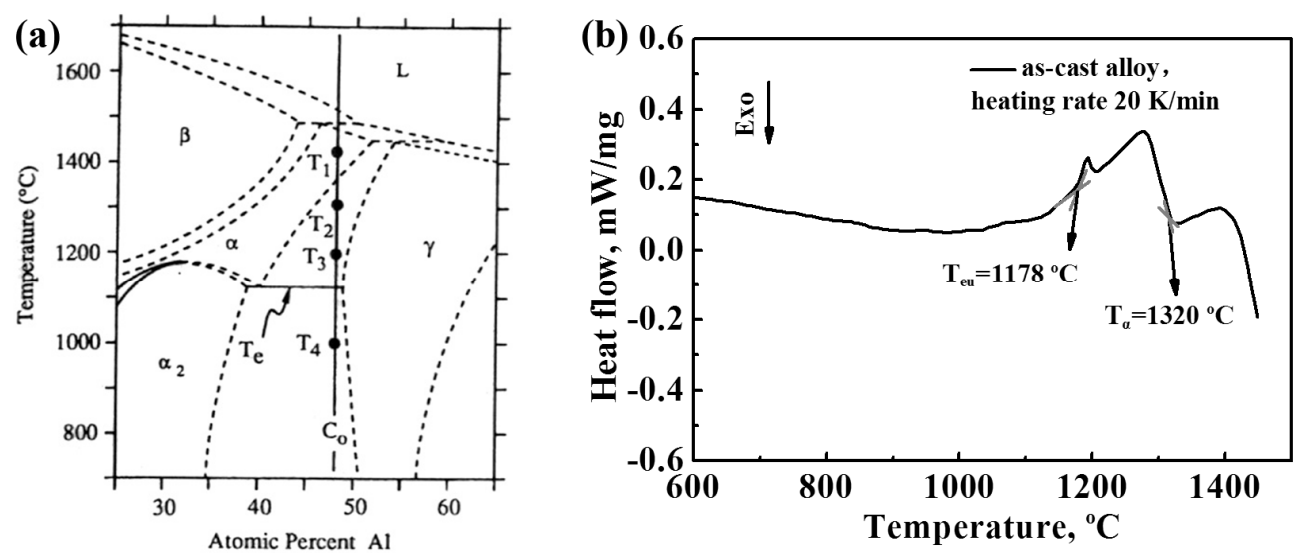

Figure 5. (a) Central portion of the binary Ti-Al phase diagram as described by Kothari et al. [22]; (b) heat flux DSC trace obtained from Ti-44Al-4Nb-1.5Cr-0.5Mo-0.2B alloy.

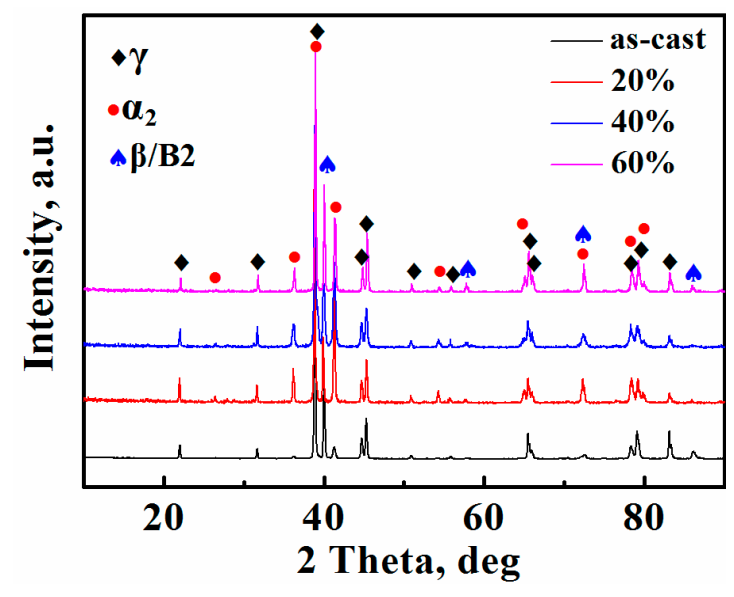

Figure 6. XRD patterns obtained from as-cast Ti- $44 \mathrm{Al}-4 \mathrm{Nb}-1.5 \mathrm{Cr}-0.5 \mathrm{Mo}-0.2 \mathrm{~B}$ alloy, $20 \%$ reduction sample, $40 \%$ reduction sample and $60 \%$ reduction sample. 

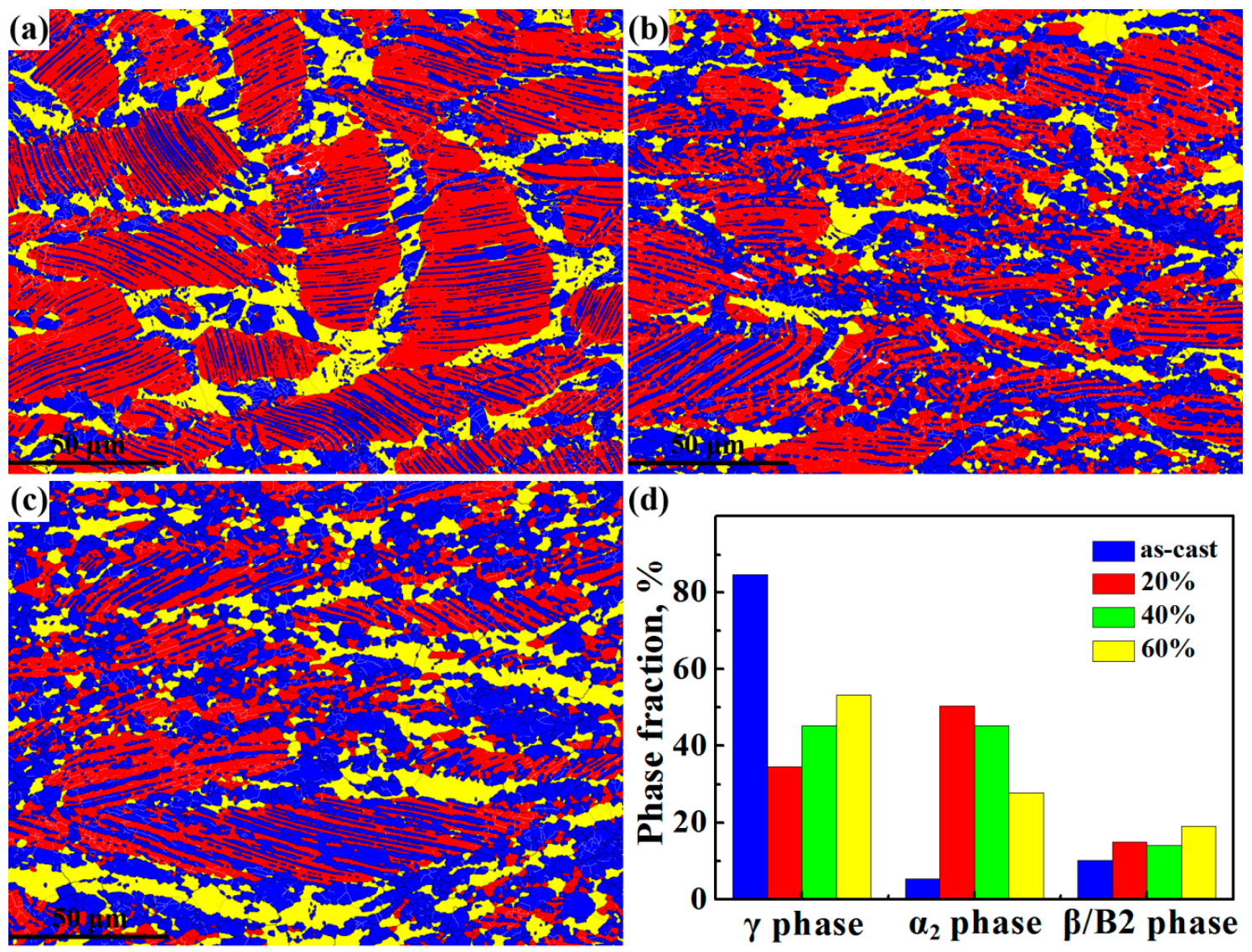

$\gamma$ phase
$\boldsymbol{\alpha}_{2}$ phase

B/B2 phase

Figure 7. Phase maps of Ti- $44 \mathrm{Al}-4 \mathrm{Nb}-1.5 \mathrm{Cr}-0.5 \mathrm{Mo}-0.2 \mathrm{~B}$ alloy compressed at $1473 \mathrm{~K}$ with a strain rate of $0.01 \mathrm{~s}^{-1}$ : (a) 20\% reduction; (b) 40\% reduction; (c) 60\% reduction; and (d) phase fraction graph.

\subsection{Lamellar Orientation Evolution}

Figure $8 \mathrm{a}, \mathrm{c}, \mathrm{e}$ show the IPF maps of the $\alpha_{2}$ phase in $\mathrm{Sa}, \mathrm{Sb}$, and Sc, respectively. Each colony of a respective sample is denoted by $\mathrm{CxN}$ ( $\mathrm{C}$ stands for colony, $\mathrm{x}$ stands for the sample name, and $\mathrm{N}$ stands for the colony number). For example, Ca1 stands for the first colony in Sa. Figure 8b,d,f shows the pole figures corresponding to the IPF maps shown in Figure 8a,c,e, respectively. The deformation modes are defined by the angle $\varphi$ between the compressive direction and the colony orientation [15]. The lamellar orientation is presented by the $\alpha_{2}$ colony orientation because the $\alpha_{2}$ phase is the matrix phase of the lamellar colonies and $\alpha_{2}$ laths have the same orientation in an entire colony. The colonies can be classified into three deformation modes, namely, hard mode I $\left(0^{\circ}<\varphi<15^{\circ}\right)$, soft mode $\left(15^{\circ}<\varphi<75^{\circ}\right)$, and hard mode II $\left(75^{\circ}<\varphi<90^{\circ}\right)$ [1]. In Sa, several colonies, namely, Ca2, Ca5, Ca7, Ca8, Ca12, and $\mathrm{Ca} 13$, retained their own orientations. The deformation mode of $\mathrm{Ca} 2, \mathrm{Ca} 5, \mathrm{Ca} 7, \mathrm{Ca} 8$, and Ca12 was hard mode I, whereasthe deformation mode of Ca13 was hard mode II. Additionally, the orientations of the other colonies varied continuously. The most common deformation mode in the colonies was the soft mode, except for $\mathrm{Ca} 6$, in which the mode varied from hard mode II to soft mode. The orientation ofthe $\alpha_{2}$ laths in $\mathrm{Ca} 15$ rotated over $40^{\circ}$, and $\mathrm{Ca} 4, \mathrm{Ca} 5, \mathrm{Ca} 6$, and $\mathrm{Ca} 7$ began to spheroidize or decompose. The spheroidization behavior of the lamellae strongly depended on the orientation, and the lamellae in hard modes I and II had a higher tendency to spheroidize than those in soft mode. These results are consistent with those of previous research [25]. In Sb, with anincrease in deformation, nearlyall 
of the colonies were deformed or spheroidized. For example, several laths in $\mathrm{Cb} 9, \mathrm{Cb} 10$, and Cb12 remained, whereas the rest were spheroidized. This phenomenon is illustrated in Figure $9 \mathrm{c}$, which depicts that the lamellae were spheroidized and affected by $\gamma$ twins, as reported by a similar study [26]. Local shear deformation may have occurred in certain colonies, such as $\mathrm{Cb} 6, \mathrm{Cb} 14$, and $\mathrm{Cb} 16$, thereby producing kink bands. The kink bands led to a rotation of the lamellae from hard mode I to soft mode. Figure $9 \mathrm{~b}$ shows the kink band in the colony. One identity lamella transformed into two pieces with a kink bend between them due to the shear stress. The original colonies in hard mode I disappeared and transformed into colonies in soft mode because of kink bends. In Sc, fewer colonies remained because of the expansion of the DRX region, most of which were in soft mode (Cc1, Cc2, Cc6, Cc7, and $\mathrm{Cc} 8)$ or hard mode II (Cc3, Cc4, and Cc5). Notably, colonies tended to rotate during compression in soft mode in each sample [27]. The pole figures (Figure $8 \mathrm{~b}, \mathrm{~d}, \mathrm{f}$ ) confirm the previous discussion in this section. The colonies had a weak texture at the early deformation stage, and all three modes of colonies appeared in Sa. With an increase in deformation, the colonies in hard mode I transformed into colonies in soft mode by kinking, and the colonies in soft mode rotated close to the orientation in hard mode I. By contrast, the colonies in hard mode II spheroidized and retained their own orientation. Strong texture components were observed in the remnant colonies.

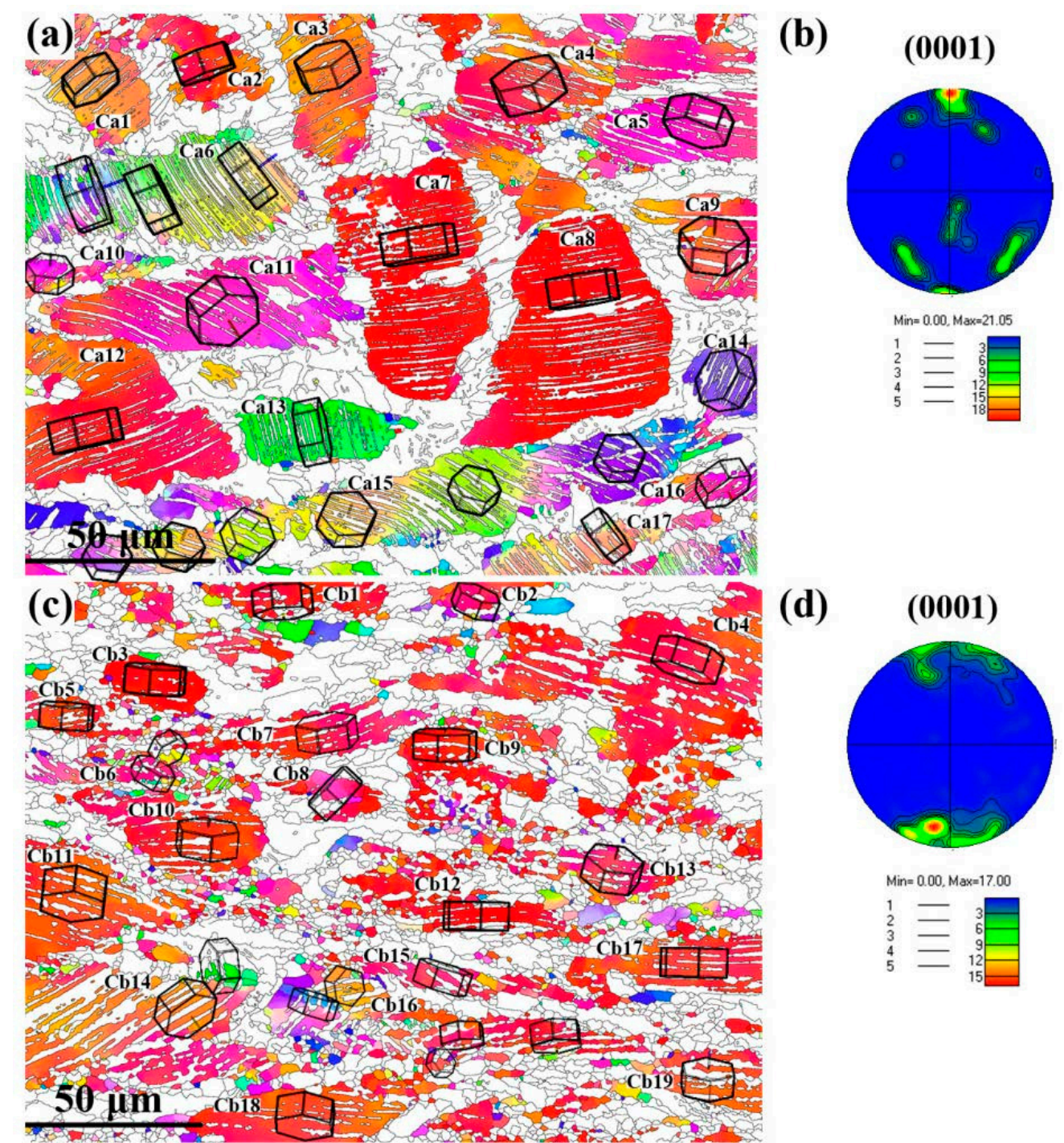

Figure 8. Cont. 

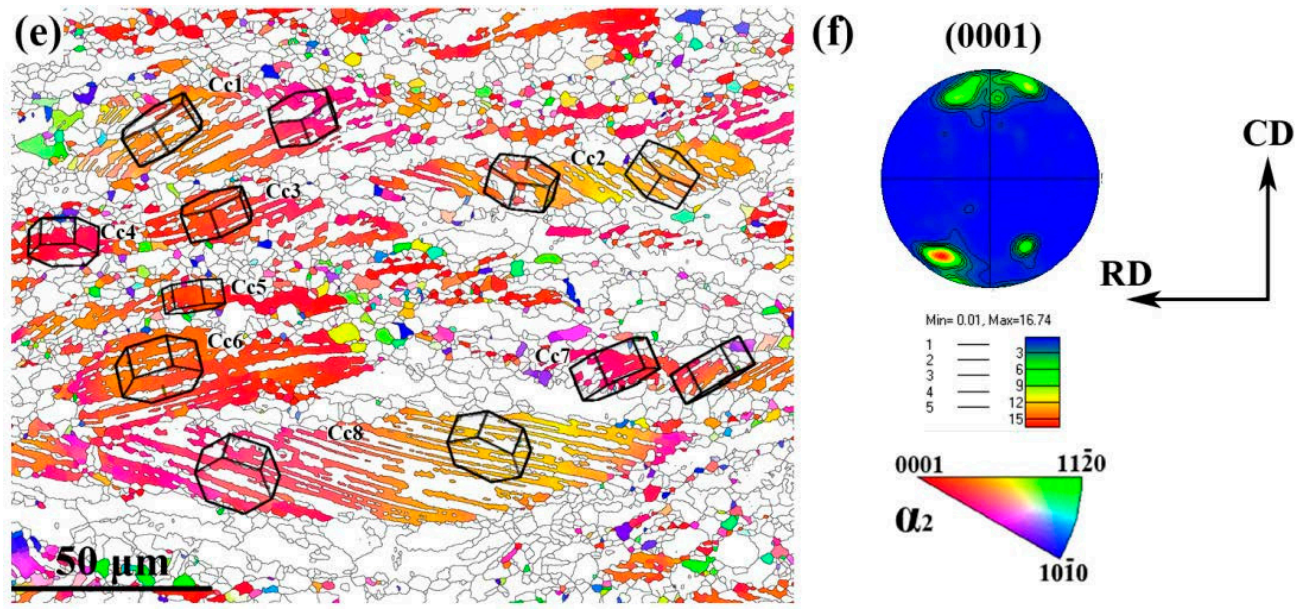

Figure 8. IPF maps and corresponding pole figures of the $\alpha_{2}$ phase of Ti-44Al-4Nb-1.5Cr-0.5Mo-0.2B alloy: (a,b) 20\% reduction, (c,d) 40\% reduction, and (e,f) 60\% reduction. CD denotes the compressive direction, and RD denotes the radial direction.
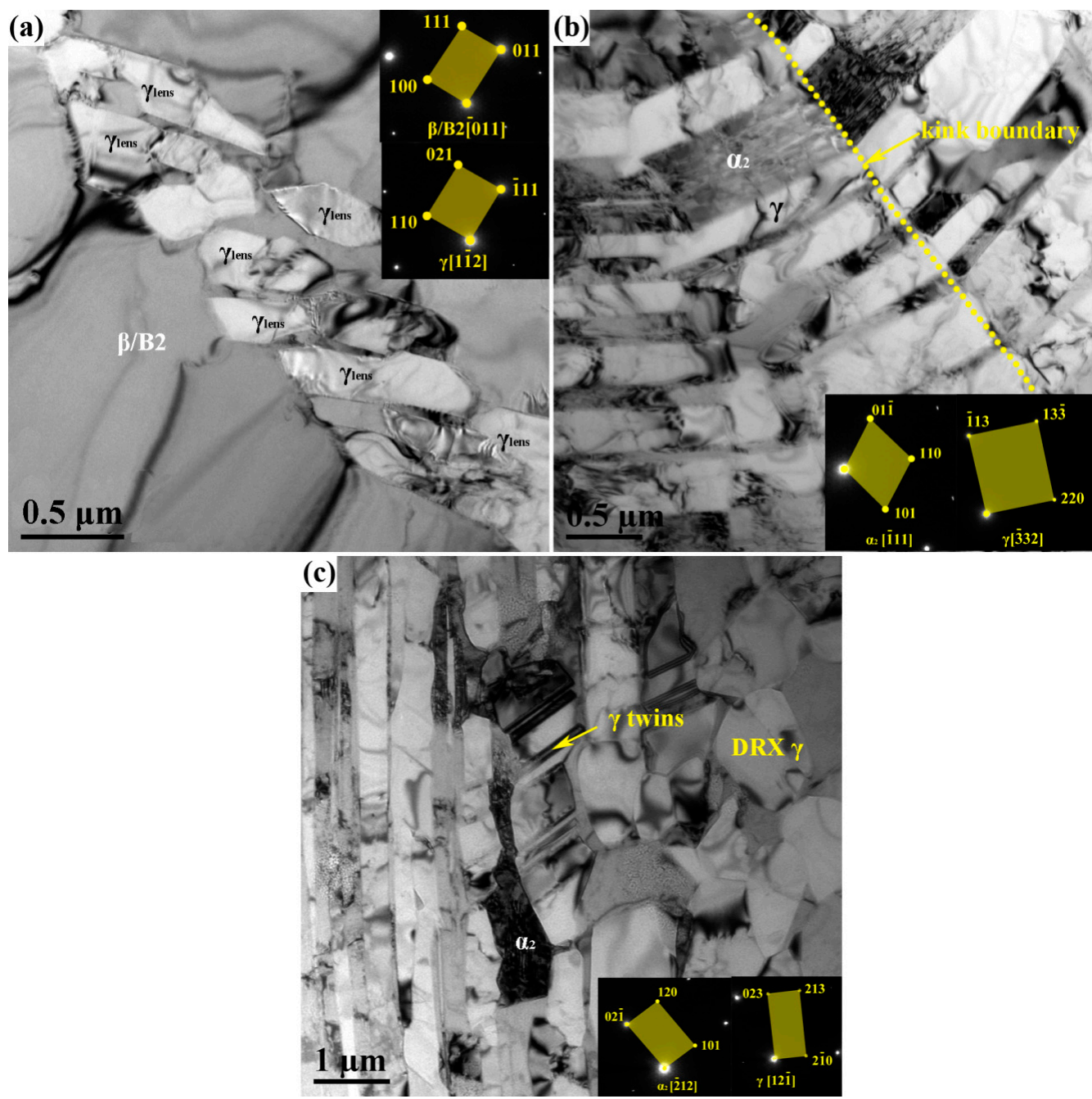

Figure 9. Bright-field TEM images showing the microstructures after $40 \%$ reduction: (a) $\gamma_{\text {lens }}$ precipitated in $\beta /$ B2 phase; (b) kink band in $\alpha_{2} / \gamma$ lamella; and (c) $\gamma$ twins and DRX $\gamma$ grains corresponding SAED patterns are shown in the corner. 


\section{Conclusions}

Various hot compression tests were conducted at a temperature of $1473 \mathrm{~K}$ and a strain rate of $0.01 \mathrm{~s}^{-1}$ to investigate the microstructure transformation and lamellar orientation evolution of Ti-44Al-4Nb-1.5Cr-0.5Mo-0.2B alloy. The following conclusions were obtained.

1. The S-S curves showed a pronounced stress peak, and with increasing strain, the flow stress continuously decreased until it reached a steady-state plateau. The dynamic softening of the S-S curves was caused by the DRX process, flow localization, and phase transitions.

2. With anincrease in deformation, the content of the $\gamma$ phase increased, whereasthe content of the $\alpha_{2}$ phase remarkablydecreased. For the $\beta /$ B2 phase, the regularity was not apparent. The phase transitions $\beta / \mathrm{B} 2 \rightarrow \gamma$ transition and $\alpha_{2} / \gamma$ lamellae $\rightarrow \gamma+\beta /$ B2 transition occurred simultaneously during the deformation at $1473 \mathrm{~K}$.

3. The deformation behavior of the colonies exhibited anisotropy. The colonies in hard mode II spheroidized and retained their own orientation, whereas the colonies in hard mode I transformed to colonies in soft mode by kinking. The colonies in soft mode rotated close to the orientation in hard mode II. The remnant colonies were close to hard mode II.

Author Contributions: K.Z., A.F. and S.Q. conceived and designed the experiments; K.Z. and J.S. performed the experiments; all authors analyzed the data and discussed the results; K.Z. and J.S. wrote the paper.

Acknowledgments: The authors are grateful to the financial support from the National Natural Science Foundation of China (NSFC) (Grant Nos. U1302275, 51305304 and 51701116), the Fundamental Research Funds for the Central Universities, and the Major Science and Technology Project "High-end CNC Machine Tools and Basic Manufacturing Equipment" (2013ZX04011061).

Conflicts of Interest: The authors declare no conflict of interest.

\section{References}

1. Appel, F.; Paul, J.D.H.; Oehring, M. Gamma Titanium Aluminide Alloys: Science and Technology; Wiley-VCH: Weinheim, Germany, 2011.

2. Kim, Y.-W. Gamma titanium aluminides. JOM 1995, 47, 38. [CrossRef]

3. Clemens, H.; Mayer, S. Advanced intermetallic TiAl alloys. Mater. Sci. Forum 2017, 879, 113-118. [CrossRef]

4. Clemens, H.; Wallgram, W.; Kremmer, S.; Güther, V.; Otto, A.; Bartels, A. Design of novel $\beta$-solidifying TiAl alloys with adjustable $\beta$ /B2-phase fraction and excellent hot-workability. Adv. Eng. Mater. 2008, 10, 707-713. [CrossRef]

5. Kim, Y.-W.; Dimiduk, D.M. Progress in the understanding of gamma titanium aluminides. JOM 1991, 43, 40-47. [CrossRef]

6. Fujitsuna, N.; Ohyama, H.; Miyamoto, Y.; Ashida, Y. Isothermal forging of TiAl-based intermetallic compounds. ISIJ Int. 1991, 31, 1147-1153. [CrossRef]

7. Tetsui, T.; Shindo, K.; Kaji, S.; Kobayashi, S.; Takeyama, M. Fabrication of TiAl components by means of hot forging and machining. Intermetallics 2005, 13, 971-978. [CrossRef]

8. Liu, R.; Liu, D.; Tan, J.; Cui, Y.; Yang, R.; Liu, F.; Withey, P.A. Textures of rectangular extrusions and their effects on the mechanical properties of thermo-mechanically treated, lamellar microstructure, Ti-47Al-2Cr-2Nb-0.15B. Intermetallics 2014, 52, 110-123. [CrossRef]

9. Zhou, H.; Kong, F.; Wu, K.; Wang, X.; Chen, Y. Hot pack rolling nearly lamellar Ti-44Al-8Nb-(W, B, Y) alloy with different rolling reductions: Lamellar colonies evolution and tensile properties. Mater. Des. 2017, 121, 202-212. [CrossRef]

10. Appel, F.; Clemens, H.; Fischer, F.D. Modeling concepts for intermetallic titanium aluminides. Prog. Mater. Sci. 2016, 81, 55-124. [CrossRef]

11. Inui, H.; Oh, M.H.; Nakamura, A.; Yamaguchi, M. Room-temperature tensile deformation of polysynthetically twinned (PST) crystals of TiAl. Acta Metall. Mater. 1992, 40, 3095-3104. [CrossRef]

12. Kishida, K.; Inui, H.; Yamaguchi, M. Deformation of PST crystals of a TiAl/ $\mathrm{Ti}_{3} \mathrm{Al}$ two-phase alloy at $1000{ }^{\circ} \mathrm{C}$. Intermetallics 1999, 7, 1131-1139. [CrossRef] 
13. Brockman, R.A. Analysis of elastic-plastic deformation in TiAl polycrystals. Int. J. Plast. 2003, 19, 1749-1772. [CrossRef]

14. Rester, M.; Fischer, F.; Kirchlechner, C.; Schmoelzer, T.; Clemens, H.; Dehm, G. Deformation mechanisms in micron-sized PSTTiAl compression samples: Experiment and model. Acta Mater. 2011, 59, 3410-3421. [CrossRef]

15. Edwards, T.E.J.; Di Gioacchino, F.; Muñoz-Moreno, R.; Clegg, W.J. Deformation of lamellar TiAl alloys by longitudinal twinning. Scr. Mater. 2016, 118, 46-50. [CrossRef]

16. Schwaighofer, E.; Clemens, H.; Lindemann, J.; Stark, A.; Mayer, S. Hot-working behavior of an advanced intermetallic multi-phase $\gamma$-TiAl based alloy. Mater. Sci. Eng. A 2014, 614, 297-310. [CrossRef]

17. Kainuma, R.; Fujita, Y.; Mitsui, H.; Ohnuma, I.; Ishida, K. Phase equilibria among $\alpha$ (hcp), $\beta$ (bcc) and $\gamma$ (110) phases in Ti-Al base ternary alloys. Intermetallics 2000, 8, 855-867. [CrossRef]

18. Clemens, H.; Mayer, S. Design, processing, microstructure, properties, and applications of advanced intermetallic TiAl alloys. Adv. Eng. Mater. 2013, 15, 191-215. [CrossRef]

19. Blackburn, M.J. Some aspects of phase transformations in titanium alloys. Sci. Technol. Appl. Titan. 1970, 639-642. [CrossRef]

20. Prasad, Y.; Rao, K.; Sasidhar, S. Hot Working Guide: A Compendium of Processing Maps; ASM International: Materials Park, OH, USA, 2015.

21. Niu, H.Z.; Chen, Y.F.; Zhang, Y.S.; Lu, J.W.; Zhang, W.; Zhang, P.X. Phase transformation and dynamic recrystallization behavior of a $\beta$-solidifying $\gamma$-TiAl alloy and its wrought microstructure control. Mater. Des. 2016, 90, 196-203. [CrossRef]

22. Kothari, K.; Radhakrishnan, R.; Wereley, N.M. Advances in gamma titanium aluminides and their manufacturing techniques. Prog. Aerosp. Sci. 2012, 55, 1-16. [CrossRef]

23. Schwaighofer, E.; Clemens, H.; Mayer, S.; Lindemann, J.; Klose, J.; Smarsly, W.; Güther, V. Microstructural design and mechanical properties of a cast and heat-treated intermetallic multi-phase $\gamma$-TiAl based alloy. Intermetallics 2014, 44, 128-140. [CrossRef]

24. Niu, H.Z.; Chen, Y.Y.; Zhang, Y.S.; Lu, J.W.; Zhang, W.; Zhang, P.X. Producing fully-lamellar microstructure for wrought beta-gamma TiAl alloys without single $\alpha$-phase field. Intermetallics 2015, 59, 87-94. [CrossRef]

25. Imayev, R.; Imayev, V.; Oehring, M.; Appel, F. Microstructural evolution during hot working of Ti aluminide alloys: Influence of phase constitution and initial casting texture. Mater. Trans. A 2005, 36, 859-867. [CrossRef]

26. Hao, Y.; Liu, J.; Li, S.; Li, J.; Liu, X.; Feng, X. Effects of nano-twinning on the deformation and mechanical behaviours of TiAl alloys with distinct microstructure at elevated loading temperatures. Mater. Sci. Eng. A 2017, 705, 210-218. [CrossRef]

27. Patriarca, L.; Filippini, M.; Beretta, S. Digital image correlation-based analysis of strain accumulation on a duplex $\gamma$-TiAl. Intermetallics 2016, 75, 42-50. [CrossRef] 